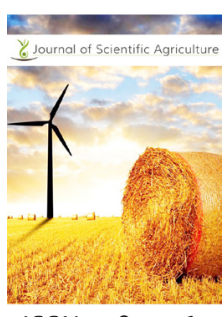

ISSN: $2184^{-0261}$

Received: Feb 11, 2020

Accepted: May 13, 2020

Published: May 18, 2020

*Corresponding author: Abdul Rasool Atayee

E-mail: abdulrasool.

atayee2018@gmail.com

\section{Alleviation of cold stress in vegetable crops}

\author{
Abdul Rasool Atayee* and Mohammad Safar Noori \\ Faculty of Agriculture, Takhar University, Afghanistan
}

\begin{abstract}
Low temperature is a major environmental factor that limits crop productivity of plants. Cold stress is a serious threat to the sustainability of crop yields. Low temperature has a huge impact on the survival and geographical distribution of plants. It negatively affects cellular components and metabolism, and temperature extremes impose stresses of variable severity that depend on the intensity and duration of the stress. Low temperature (less than minimum) leads to chlorosis, necrosis, membrane damage, changes in cytoplasm viscosity, and changes in enzyme activities leading to death of plant. Cold stress disrupts the integrity of intracellular organelles, leading to the loss of compartmentalization. It also causes reduction and impairing of photosynthesis, protein assembly and general metabolic processes. Moreover, cold stress during anthesis induces flower dropping, sterility of pollen, pollen tube distortion, ovule abortion and reduced fruit set, which leads to declined growth and lower yield. A number of approaches are being used to mitigate the deleterious effects of cold stress which threatens the successful vegetable crop production, application of plant growth regulators (salicylic acid, abscisic acid, jasmonic acid, Gibberellin and brassinosteroids) and unitization of genetics tools and plant breeding is one of the strategies to alleviate the low temperature stress in vegetable crops. Plant growth regulators play a greater role in improving the cold stress tolerance. In this paper, the effects of cold stress on vegetable growth, productivity and physiological activities were discussed, and some effective techniques for the mitigation of cold stress that help sustainable vegetable production under fluctuating climate is presented.
\end{abstract}

KEYWORDS: Cold stress, Alleviation, plant growth regulators, vegetable, genetic tools

\section{INTRODUCTION}

Environmental stress such as cold, heat, salinity and drought adversely affect growth and productivity and trigger a series of morphological, physiological, biochemical and molecular changes in plants that eventually interrupt plant life [1]. Stress can be defined as any substance or condition which stops a plant's metabolism, development or growth [2]. Any element that decreases plant reproduction and development below the genotype's potential considered as stress [3]. Cold stress (chilling and freezing) affect crop productivity because many crops are sensitive and intolerant to low temperature. Acute temperature variation damages the plants [4]. Usually, chilling and freezing stress lead to chlorosis, necrosis, membrane damage, changes in cytoplasm viscosity, and changes in enzyme activities [5] leading to death of plants.

Vegetables are sensitive crops and their production is hindered by various abiotic stresses. During winter season, low temperature stress adversely damages vegetable production. Low temperature stress has been reported as one of the most restraining environmental factors for agricultural crops, particularly vegetables, which accounts for significant crop losses [6]. Summer vegetables are sensitive to chilling temperature $\left(0-15^{\circ} \mathrm{C}\right)$ throughout plant development i.e. seed germination, vegetative growth and reproduction.

Low temperature stress affects the reproductive stages of plant with delayed flowering which makes the pollen sterile that severely affects the crop yield [6,7]. Low temperature stress also limits the agricultural productivity of plants in hilly areas and has a major impact on the survival and geographical distribution of the plants. The plant growth and crop productivity gets disturbed which results in substantial crop failure [8]. Low temperature induced change in membrane fluidity is one of the immediate consequences in plants during low temperature stress and might represent a potential site of perception and/or injury [9]. It is well documented that freeze-induced production of reactive oxygen species contributes to membrane damage and that intercellular ice can form adhesions with cell walls and membranes and cause cell rupture [10].

As temperatures drops below $0^{\circ} \mathrm{C}$, ice formation is generally initiated in the intercellular spaces in the extracellular fluid having a higher freezing point (lower solute concentration) than the intracellular fluid [11]. Low temperature stress during

Copyright: ๑) The authors. This article is open access and licensed under the terms of the Creative Commons Attribution License (http://creativecommons.org/licenses/by/4.0/) which permits unrestricted, use, distribution and reproduction in any medium, or format for any purpose, even commercially provided the work is properly cited. Attribution - You must give appropriate credit, provide a link to the license, and indicate if changes were made. 
reproductive development induces flower abscission, pollen sterility, pollen tube distortion, ovule abortion and reduced fruit set, which ultimately lowers yield [12]. Low temperatures favours female flower production, which is desirable and high temperatures lead to production of more male flowers. Cauliflower performs well in the temperature range of $15-25^{\circ} \mathrm{C}$ with high humidity. Though some varieties have adapted to temperatures over 300, most varieties are sensitive to higher temperatures and delayed curd initiation is observed. In onion temperature increase above $40^{\circ} \mathrm{C}$ reduced the bulb size and increase of about $3.0^{\circ} \mathrm{C}$ above $38^{\circ} \mathrm{C}$ reduced yield by $19 \%$. Warmer temperatures shorten the duration of growth leading to lower crop yields. In potato, reduction in marketable grade tuber yield to the extent of $10-20 \%$ is observed due to high temperature and frost damage reduced tuber yield by $10-50 \%$, depending upon intensity and stage of occurrence. Temperature increase beyond $20^{\circ} \mathrm{C}$ during winter affects cultivation of seasonal button mushroom and increased incidence of diseases [13]. Low temperature limits the geographical distribution of plant species and significantly decreases the yield of several crops around the world [14]. It is very important to study the frost damage mechanism and to breed cold-tolerant varieties since the average minimum temperature is below $0^{\circ} \mathrm{C}$ in about $64 \%$ of the earth's land area and it is below $-10^{\circ} \mathrm{C}$ in about $48 \%$ [15].

Vegetables have an imperative role to play in the diversification of agriculture. They ensure food and nutritional security of human. However, vegetables are sensitive crops and their production is hindered by various abiotic stresses. Low temperature stress has been reported as one of the most restraining environmental factors for vegetables, which accounts for significant crop losses. The demand for food and vegetables will continue to rise with the increase in global population; therefore improving productivity to ensure sustainable yields under changing environmental conditions is imperative. Development of methods to enhance stress tolerance in vegetable crops is crucial and need based [16].

Application of plant growth regulators in one the effective approaches which alleviate the detrimental effects of cold stress in plants. Salicylic acid (SA) application significantly increased the number of fruits in pepper [17] and cucumber [18]. Foliar application of SA increased cold tolerance of cucumber [19]. The lower concentration of SA and acetyl salicylic acid (0.1 $\mathrm{mM}$ and $0.5 \mathrm{mM}$ ) have been found more effective against cold stress in tomato and bean plants [20].

Exogenous application of abscisic acid (ABA) induced the expression of specific Late embryogenesis abundant (LEA) genes in plant vegetative tissues [21]. The role of abscisic acid in the up-regulation of LEA genes is considered to be one of the mechanisms that $\mathrm{ABA}$ has to increase plant freezing tolerance [22]. Jasmonic acid (JA) plays key role in alleviating the damaging effects under adverse conditions. They regulate gene expression in plant systems which controls overall plant growth, antioxidant metabolism, osmolyte synthesis, metabolite accumulation, and physiological parameters. It has been proved that the external application of JA significantly enhanced cold tolerance in plants [23]. Gibberellin (GA) is involved in the expression of CRT/DRE-binding factor gene which in turn confers tolerance to drought, salt and cold stress. Moreover, GA is associated with SA/JA balance in the CBF-mediated stress response [24]. Brassinosteroids (BRs) have been explored for stress-protective properties in plants against a number of abiotic stresses [25]. BRs mitigated the damaging effect of chilling stress and increased the growth of cucumber seedlings [26]. BRs effectively mitigated the negative effects of chilling stress in tomato [27] and increased the growth of cucumber seedlings under cold stress conditions [28]. BRs enhanced the activities of Calvin cycle enzymes, improved the antioxidative system, and protected the photosynthetic apparatus from cold-induced damage in Cucumis sativus plants which resulted in alleviation of the photo oxidative stress during the recovery process from chilling injury [29]. Phytohormones engineering is very promising in plant response to environmental stresses; however, more research is still needed in this field [30]. Other hormones such as ethylene and cytokinin also have an important role in cold tolerance. Although it has been found that cytokinin content was decreased in plants exposed to stress, the next application of cytokinin improved cold tolerance in plant. Stress-related genes at transcriptional level pattern have been identified by cytokinin but the exact role of cytokinin in cold stress is still unknown [31].

The tolerance to cold stress is a complicated process and involves morphological, physiological and biochemical modifications. Therefore, it is necessary to alleviate the adverse effects of cold stress in vegetable crops through some effective strategies. The aim of this review article is to highlight the effects of cold stress in vegetable crops and present the strategies to alleviate the detrimental effects of cold stress and pave the way for the sustainable vegetable crops production under challenging environmental conditions.

\section{EFFECT OF COLD STRESS ON VEGETABLE GROWTH AND PRODUCTIVITY}

Plants exposed to cold stress show various phenotypic symptoms that include reduced leaf expansion, wilting and chlorosis (yellowing of leaves) and may lead to necrosis (death of tissue). However, the appearance of injury symptoms depends upon the sensitivity of a plant to cold stress and varies from plant to plant. Cold stress-induced injury in plants may appear after 48 to $72 \mathrm{~h}$ of stress exposure [32]. Under low temperatures, lots of seeds do not germinate or germinate irregularly and plants grow differentially with delayed plant formation leading to variability in crop development. During later stages, plant growth and development are extremely retarded that either limit or lead to no flower and fruit production [33].

Weak fruit set after a cold period could be due to the poor pollen viability [34]. Cold stress, which includes chilling $\left(<20^{\circ} \mathrm{C}\right)$ and/ or freezing $\left(<0^{\circ} \mathrm{C}\right)$ temperatures, adversely affects the growth and development of plants. Chilling and freezing are stresses that show different effects on plants: the first leads to slow biochemical reactions, such as enzyme and membrane transport activities; the second leads to ice crystal formation that can cause the disruption of cell membrane system [35]. 
In potato, frost damage reduced tuber yield by $10-50 \%$, depending upon intensity and stage of occurrence [13]. Cold stress results in poor germination, stunted seedlings, yellowing of leaves, withering and reduced tillering. The effects of cold stress at the reproductive stage of plants delay heading and result in pollen sterility, which is the key factors responsible for the reduction in yield [6]. Spring frost injury is a persistent hazard in the early vegetable and processing tomato industries [32]. Low temperature stress adversely affects growth, productivity and triggers a series of morphological, physiological and biochemical changes in plants. The demand for food and vegetables will continue to rise with the increase in global population; therefore improving productivity to ensure sustainable yields under changing environmental conditions is needed [36].

\section{EFFECT OF COLD STRESS ON PHYSIOLOGICAL ACTIVITIES OF VEGETABLES}

Some plants have morphological adaptations in order to avoid undesirable conditions and others can alter their physiology metabolism, gene expression and various developmental activities to tolerate the effect of specific stresses [22]. Research findings have shown that plants native to warm habitats show symptoms of injury upon exposure to low non-freezing temperatures. For example, plants such as soybean (Glycine max) and tomato (Lycopersicon esculentum) exhibit the signs of injury when they are exposed to temperatures below $10-15^{\circ} \mathrm{C}[37,38]$.

The major adverse effect of cold stress in plants has been seen in terms of plasma membrane damage. This has been documented due to cold stress-induced dehydration [39]. Cold-sensitive plants usually have a higher proportion of saturated fatty acids in their plasma membrane. Therefore, cold-sensitive plants have a higher transition temperature. On the contrary, cold-resistant plants have a higher proportion of unsaturated fatty acids and hence a lower transition temperature. Understanding of how cold stress induces its damaging effects on plants is crucial for the development of frost-tolerant crops. It has been revealed that cold-induced ice formation is the real cause of plant injury. Ice formation in plant tissues during cold stress leads to dehydration. Ice is formed in the apoplastic space of a plant tissue because that has relatively lower solute concentration. It is known that the vapor pressure of ice is much lower than water at any given temperature [32]. Therefore, ice formation in the apoplast establishes a vapor pressure gradient between the apoplast and surrounding cells. As a result of this gradient, the cytoplasmic water migrates down the gradient from the cell cytosol to the apoplastic space. This adds to existing ice crystals in the apoplastic space and causes a mechanical strain on the cell wall and plasma membrane, leading to cell rupture [40].

Cold stress alters lipid composition of the biomembranes, affecting their fluidity [4l], certain additional factors may also contribute to damage induced by cold stress. This includes synthesis and accumulation of compatible solutes, the synthesis of cold acclimation-induced proteins [42], changes in the carbohydrate metabolism $[43,44]$ and the boosting of the radical scavenging potential of the cells [45].

Cold stress induces the accumulation of proline, a wellknown osmoprotectant. It also affects virtually all aspects of cellular function in plants. One of the major influences of cold stress-induced dehydration is membrane disintegration. Such changes caused by cold stress adversely affect the growth and development of plants [32]. Cold stress disrupts the integrity of intracellular organelles, leading to the loss of compartmentalization. Exposure of plants to cold stress also causes reduction and impairing of photosynthesis, protein assembly and general metabolic processes. However, metabolite profiles in Arabidopsis do not appear to correlate with cold acclimation capacity [46].

\section{METHODS OF INDUCING COLD STRESS TOLERANCE IN VEGETABLES}

The plants have several mechanisms or approaches to cope with low temperature stress. Cold acclimation is a key approach to stabilize membranes against freezing injury. It prevents expansion-induced-lyses and the formation of hexagonal II phase lipids in plants. Multiple mechanisms appear to be involved in this stabilization. The best documented are changes in lipid composition [39]. Similarly, the accumulation of sucrose and other simple sugars that typically occurs with cold acclimation also seems likely to contribute to the stabilization of membranes as these molecules can protect membranes against freeze-induced damage in vitro [47]. There is some evidence that certain novel hydrophilic and late embryogenesis abundant (LEA) proteins also participate in the stabilization of membranes against freezeinduced injury. These hydrophilic and LEA proteins are predicted to contain regions capable of forming amphipathic $\alpha$-helices which are shown to have strong effect on intrinsic curvature of monolayers and their propensity to form hexagonal II phase. They are said to defer their formation at lower temperatures [48].

Another mechanism which helps plants to cope with the low temperature stress might be the extensive water binding capacity of hydrophilic proteins which provide a protective environment in the proximity of stabilization. Although freezing injury results primarily from membrane lesions caused by cellular dehydration, additional factors may also contribute to freezing-induced cellular damage [11]. The enhancement of antioxidative mechanisms [49], increased levels of sugars in the apoplastic space [50] and the induction of genes encoding molecular chaperones, respectively, could have protective effects to reduce the freeze induced cellular damage. There are different approaches which can be utilized for the alleviation of cold stress in vegetable crops such as application of plant growth regulators and genetic tools.

\section{APPLICATION OF PLANT GROWTH REGULATORS FOR ALLEVIATION OF COLD STRESS}

Plant growth regulators (PGRs) are one of the possible approaches that induce cold stress tolerance in pants. Several 
PGRs have been evaluated for the mitigation of cold stress in plants in recent years.

\section{Salicylic Acid (SA)}

SA, a plant produced phenolic compound is an endogenous plant growth regulator which generates a wide range of metabolic and physiological responses in plants affecting their growth and development. It has been reported that foliar application of SA increased the number of fruits in pepper (Capsicum annum L.) and cucumber (Cucumis sativus L.) significantly $[17,18]$. Several studies revealed that application of phenolic compounds were able to reduce chilling symptoms in tomato fruits [51]. Application of SA significantly enhanced the amount of vitamin $\mathrm{C}$, lycopene and also increased rate of pressure tolerance of fruits, improved quantity and quality of tomato fruits [52].

In tomato and bean plants, the lower concentration of SA and acetyl salicylic acid $(0.1 \mathrm{mM}$ and $0.5 \mathrm{mM})$ effectively alleviated low temperature stress [20]. SA enhanced plant cell division and growth through regulation of other hormones [53] and mitigating abiotic stresses by increasing the growth regulating hormones like auxins and cytokinins [54]. Exogenous application of SA enhanced total soluble sugar and soluble protein of cowpea plants [55]. It plays a significant role in the regulation of physiological and molecular mechanisms to acclimatize plants in extreme environmental conditions and is believed to have a role in plant's response to abiotic stress [36]. The over-accumulation of SA in several mutants of Arabidopsis caused a freezing sensitivity [56]. It seems that treatment duration and the concentration of SA play essential roles in the response of plant species [22]. Salicylic acid is a vital signal molecule for modulating plant response to various abiotic stresses including low temperature stress [17]. SA-induced alleviation of cold stress has been reported in tomato, cucumber, squash, and watermelon [57].

\section{Abscisic Acid (ABA)}

ABA plays an important role in the induction of LEA gene expression [58]. Application of exogenous ABA-induced the expression of specific LEA genes in plant vegetative tissues [21]. The expression of LEA genes during the development of seed and under abiotic stress was up-regulated by ABA [59]. It has also been reported that ABA induces the expression of LEA genes resulting in an increase in the desiccation tolerance of cultured embryos [60]. The role of ABA in the up-regulation of LEA genes is considered to be one of the mechanisms that ABA has to increase freezing tolerance in plants [22]. Research findings indicated that cold-acclimation induced chilling tolerance in chick pea was associated with marked increase in endogenous ABA, cryoprotective solutes, antioxidative enzymes like ascorbate, glutathione, superoxide dismutase and catalase, relative growth rate of roots and significant decrease in electrolyte leakage and oxidative damage [61]. Some previous observations on this aspect also related higher chilling tolerance imparted by cold acclimation to elevated endogenous ABA [62].

\section{Jasmonic Acid (JA)}

JA as an important regulatory signal plays a key role in plant cold tolerance $[63,64]$. External application of JA significantly enhanced cold tolerance in plants with or without acclimation. Moreover, blocking of the endogenous JA increased the sensitivity to the cold stress. It has been reported that JA up-regulated the CBF/DREBl signaling pathway [65]. JA and its methyl ester play a significant role in plant growth and developmental processes under changing environmental as well as other biotic stresses. It has been established that JA are emerging players in alleviating the deleterious effects under adverse conditions. They induce resistance against many biotic stresses. In plant systems, they regulate gene expression which controls overall plant growth, antioxidant metabolism, osmolyte synthesis, metabolite accumulation, and physiological parameters [23]. Experiment on Arabis alpina belonging to Brassicaceae family showed variation in JA and other hormones under chilling and freezing conditions [66]. All tolerant and non-tolerant plants showed very high level of JA at normal temperature of $22^{\circ} \mathrm{C}$. After chilling stress at $4^{\circ} \mathrm{C}$, the tolerant plants did not show considerable change in JA relative to 10 -fold reduction in nontolerant plants. Upon exposure to frost (below $0{ }^{\circ} \mathrm{C}$ ), JA content drastically dropped in tolerant plants while the nontolerant plants had nearly the same level of JA. It indicates that in A. alpina, JA may be the principal jasmonate mediator of the cold stress [23].

\section{Gibberellin (GA)}

GA or gibberellic acid is the plant hormone altered in plants under cold stress. GA plays a crucial role in the plant growthregulatory mechanisms. It has been found that GA is involved in the expression of CRT/DRE-binding factor gene which in turn confers tolerance to cold stress. Moreover, GA is associated with SA/JA balance in the CBF-mediated stress response [24]. The key components of GA is the nuclear localized proteins (DELLA) that repress plant growth; however recent advances indicated that DELLA has a role in many plant growth aspects especially those that are affected by environmental stresses. Investigation on the relationship between $\mathrm{CBF} 1$ and $\mathrm{GA}$ pathways indicates that constitutive expression of CBFl leads to less bioactivity of GA resulting in dwarfism in plants and delay in flowering [67]. RGL genes, which code for DELLA proteins, act to restrain growth, whereas GA promotes growth by overcoming DELLA-mediated growth restraint [68] resulting to tolerate cold stress.

\section{Brassinosteroids (BRs)}

BRs are group of plant growth regulators with significant growth promoting activity. BRs were initially extensively studied for their profound growth promoting physiological responses such as growth and yield, seed germination, photosynthesis, senescence, photomorphogenesis and flowering. BRs have been studied for its stress-protective characteristics in plants against a number of abiotic stresses [25]. 
Application of BRs alleviated the damaging effect of chilling stress and increased the growth of cucumber seedlings under cold stress conditions [26]. Foliar application of 24-epiBL (a type of BRs) mitigated the $12 / 8^{\circ} \mathrm{C}$ chilling-induced inhibition of photosynthetic capacity of cucumber (Cucumis sativus L) plants by not only decreasing the production of ROS accumulation, but also enhancing the activities of SOD, APX; decreasing $\mathrm{H}_{2} \mathrm{O}_{2}$ and MDA. Further, Cucumber plants pretreated with 24-epiBL alleviated chilling stress by regulating antioxidative enzymes (APX, GR [glutathione reductase], CAT and GPX) [69].

BL, a type of BRs effectively mitigated the detrimental effects of chilling stress in tomato [27] and increased the growth of cucumber seedlings [28]. BRs were capable of protecting the photosynthetic apparatus from cold-induced damage in Cucumis sativus plants by enhancing the activities of Calvin cycle enzymes and enhancing the antioxidative system which in turn resulted in mitigation of the photo oxidative stress during the process of recovery from chilling injury [29].

Application of 0,3 and $6 \mu \mathrm{M}$ BRs to tomato fruits stored at $1^{\circ} \mathrm{C}$ for 21 days decreased the chilling injury, electrolyte leakage, malondialdehyde (MDA) content while increased proline levels, total phenols, phenylalanine ammonia-lyase (PAL) activity and maintained the membrane integrity [70]. BRs (5, 10 and $15 \mu \mathrm{M})$ decreased the chilling injury of pepper fruit during 18-day storage at $3^{\circ} \mathrm{C}$ by decreasing the electrolyte leakage, MDA content and enhancing antioxidative enzyme (CAT, POD, APX and GR) activities [71].

BR-supplemented tomato (Lycopersicon esculentum) plants demonstrated better growth than control plants under low temperature conditions [72]. Foliar treatment of 24-epiBL resulted in enhanced photosynthesis, antioxidant defenses and protected eggplant (Solanum melongena L.) seedlings from chilling stress [73].

\section{ENHANCING COLD STRESS TOLERANCE THROUGH GENETIC AND PLANT BREEDING APPROACHES}

The applications of recombinant-DNA technology or genetic engineering in crop improvement are immense to solve the problem of global hunger as population is increasing day by day with depriving sustainable intensification. However, horticultural crops have got less attention in this area so far [74]. Research findings have shown that plants respond to low temperatures by altering mRNA levels of a large number of genes belonging to different and independent pathways. The quantitative and qualitative difference in transcriptional response to low temperature suggests the presence in higher plants of different molecular mechanisms to cold-stress response [75]. The cold induction of genes involved in calcium signaling, lipid signaling or encoding receptor-like protein kinases are also affected by the icel mutation [76,77] transformed sweet potato cv. Sushu-2 with a chloroplastic betaine aldehyde dehydrogenase (SoBADH) gene from Spinacia oleracea, which is involved in the biosynthesis of glycinebetaine. The over-expression of SoBADH gene in transgenic sweet potato improved cold tolerance by providing protection against cell damage by maintaining cell membrane integrity, stronger photosynthetic activity, reduced ROS production and activation of ROS scavenging mechanism.

The transgenic lines of tomato displayed an enhanced level of tolerance to cold conditions than normal plants as quantified by free proline, membrane stability index (MSI) and PS II activity [74]. Improved, adapted vegetable germplasm is the most cost-effective option for farmers to meet the challenges of a changing climate [78]. However, most modern cultivars represent a limited sampling of available genetic variability including tolerance to environmental stresses. Superior varieties adapted to a wider range of climatic conditions could result from the discovery of novel genetic variation for tolerance to different abiotic stresses. Genotypes with improved attributes conditioned by superior combinations of alleles at multiple loci could be identified and advanced. Improved selection techniques are needed to identify these superior genotypes and associated traits, especially from wild, related species that grow in environments, which do not support the growth of their domesticated relatives that are cultivated varieties. Plants native to climates with marked seasonality are able to acclimatize more easily to variable environmental conditions [79] and provide opportunities to identify genes or gene combinations that confer such resilience.

After the advent of Next Generation Sequencing (NGS) technologies, many horticultural crops have been sequenced, which has now solved the problem of lack of genomic information and thus facilitated the target gene/site to be modified using genome editing technology. This has also improved the breeding efficiency as various genes/QTLs coding for various horticulturally important traits have been identified. In addition to that, transcriptome sequences of a number of horticultural crops are now available in public databases. This vast information will assist in identifying various genes governing various important traits and will help in identifying the target sites for genome editing and genetic transformation [74] which consequently can help in improving stress-tolerant crops through new genetic tools and plant breeding techniques.

\section{CONCLUSION}

Cold stress is responsible for a range of physiological disturbances in chilling-sensitive plants and can cause chilling injury and death of many horticulture plants. Low temperature stress is a harsh constraint, which negatively affects vegetable crops productivity. However, several mechanisms in plants are involved in alleviating cold stress through natural tolerance system. One of the key approach is cold acclimation that helps in stabilizing membranes against freezing injury. Utilization of plant growth regulators as a new approach is very promising in plant response to environmental stresses. This review paper highlighted the role of PGRs application in enhancing the cold stress tolerance in vegetable crops and can be utilized as an effective strategy. Development of methods to enhance stress tolerance in plants is crucial and attracts considerable attention. However, more 
research is required to elucidate the effect of different PGRs on various vegetable crops and find appropriate PGR and specific dose/concentration to obtain satisfactory result in alleviating the cold stress in vegetables. Moreover, analyses of the expression of cold-regulated genes have shown the presence of multiple signal transduction pathways between the initial stress signals and gene expression. The applications of genetic engineering in vegetable crops improvement and identification, and selection of gene resources for cold stress tolerance and utilization of these genes and transcription factors in genetic modification of vegetables can improve cold tolerance and prevents yield loss in vegetable crops under low temperature conditions.

\section{AUTHORS' CONTRIBUTIONS}

Both authors have equally contributed in conceptualization, writing, review and editing of this article.

\section{ABBREVIATIONS}

ABA: Abscisic acid; APX: Ascorbate peroxidase; BRs: Brassinosteroids; CAT: Catalase; GA: Gibberellic acid; GR: Glutathione reductase $\mathrm{H}_{2} \mathrm{O}_{2}$ : Hydrogen peroxide; JA: Jasmonic acid; LEA: Late embryogenesis abundant; MDA: malondialdehyde; MSI: membrane stability index; POD: Peroxidase; PGR: plant growth regulators ROS: Reactive oxygen species; SA: Salicylic acid

\section{REFERENCES}

1. Ahmad PM, Prasad NV. Abiotic stress responses in plants: metabolism, productivity and sustainability, Springer, 2012. New York, NY, USA.

2. Lichtenthaler HK. The stress concept in plants: an introduction. Ann NY Acad Sci.: 187-198.

3. Mahmood, R. 2002. In vitro effect of salt on the vigor of potato (Solanum tuberosum L.) plantlets. Int J Biotechnol. 2006; 1:73-77.

4. Schwartz M, Ahas R, Aasa A. Onset of spring starting earlier across the northern hemisphere. Glob Chang Biol. 2006; 12: 343-351.

5. Ruelland E, Zachowski A. How plants sense temperature. Environ Exp Bot. 2010. 69:225-232.

6. Yadav S. Cold stress tolerance mechanisms in plants. A review. Agron. Sustain. Dev. 2010. 30: 515-27.

7. Suzuki K, Nagasuga K and Okada M. The chilling injury induced by high root temperature in the leaves of rice seedlings. Plant Cell Physiol. 2008; 49: 433-42.

8. Xin Z, and Browse J. Cold comfort farm: the acclimation of plants to freezing temperatures. Plant Cell Environ. 2001; 23: 893-902.

9. Orvar BL, Sangwan V, Omann F, Dhindsra RS. Early steps in cold sensing by plant cells: the role of actin cytoskeleton and membrane fluidity. The Plant J. 2000; 23:785-794.

10. Olien $\mathrm{CR}$, and Smith MN. Ice adhesions in relation to freeze stress, Plant Physiol. 1997. 60, 499-503.

11. Jan NHM, and Andrabi, KI. Cold resistance in plants: A mystery unresolved. Electronic J. of Biotech. 2009; 12:1-15.

12. Waraich EA, Ahmad R, Halim A, and Aziz T. Alleviation of temperature stress by nutrient management in crop plants. Journal of Soil Science and Plant Nutrition. 2012. 12 (2), 221-244.

13. Muralidharan B, Sadhur RA, Sharath C, Tamilselvan A, Yuvasakthi S. Effect of Climate Change on Vegetable Crops. Journal of Agroecology and Natural Resource Management. 2016; 3: 299-301.

14. Pearce RS, Fuller MP. Freezing of barley studied by infrared video thermography. Plant Physiol. 2001; 125:227-240.

15. Deane $\mathrm{C}$. Whole plant and tissue culture studies on frost tolerance in cauliflower. 1994. Ph. D thesis, The National University of Ireland.

16. Kayum A, Md., Hoy-Taek Kim, U. Kumar Nath, Jong-In Park, Kang
Hee Kho, Yong-Gu Cho, III-Sup Nou1. Research on Biotic and Abiotic Stress Related Genes Exploration and Prediction in Brassica rapa and B. oleracea: A Review. Plant Breed. Biotech. 2016; 4:135-144

17. Hayat $Q$, Hayat $S$, Irfan $M$ and Ahmad $A$. Effect of exogenous salicylic acid under changing environment-A review. Environ Experi Bot. 2010; 68: $14-25$.

18. Elvwan MWM, and Hamahyomy MAM. Improved productivity and quality associated with Salicylic acid application in greenhouse pepper. Sci Hortic. 2009; 122: 521-26.

19. Sayyari M, Ghanbari F, Fatahi S and Bavandpour F. Chilling tolerance improving of watermelon seedling by salicylic acid seed and foliar application. Not Sci Biol 2013; 1: 67-73.

20. Orabi SA, Dawood MG and Saleem SR. Comparative study between the physiological role of hydrogen peroxide and salicylic acid in alleviating low temperature stress on tomato plants grown under sandponic culture. Sci Agric. 2015; 9: 49-59.

21. Bies-Etheve N, Gaubier-Comella P, Debures A, Lasserre E, Jobet E, Raynal M, Cooke R, Delseny M. Inventory, evolution and expression profiling diversity of the LEA (late embryogenesis abundant) protein gene family in Arabidopsis thaliana. Plant Mol Biol. 2008; 67:107-124.

22. Rihan HZ, Al-Issawi M. and Michael PF. Advances in physiological and molecular aspects of plant cold tolerance. J. Plant Interactions. 2017; 12: 143-157.

23. Siddiqi KS, and Azamal Husen. Plant response to jasmonates: current developments and their role in changing environment. Bulletin of the National Research Centre. 2019; 43:153

24. Niu S, Gao Q, Li Z, Chen X, Li W. The role of gibberellin in the CBF1Mediated Stress-Response Pathway. Plant Mol Biol Rep. 2014; 32: 852-863.

25. Vardhini BV. Does Application of Brassinosteroids mitigate the Temperature Stress in Plants? Int J Earth Sci Geol. 2019; 1: 59-65.

26. He RY, Wang GJ, Wang XS. Effects of brassinolide on growth and chilling resistance of maize seedlings. ACS Symposium Series. 1991; 474: 220-230.

27. Dhaubhadel S, Chaudhary S, Dobinson KF, Krishna P. Treatment with 24-epibrassinolide, a brassinosteroid, increases the basic thermotolerance of Brassica napus and tomato seedlings. Plant Mol Biol. 1999; 40: 333- 342.

28. Katsumi M. Physiological modes of brassinolide action in cucumber hypocotyl growth. ACS Symposium Series. 1991; 474: 246-254.

29. Jiang YP, Huang LF, Cheng F. Brassinosteroids accelerate recovery of photosynthetic apparatus from cold stress by balancing the electron partitioning, carboxylation and redox homeostasis in cucumber. Physiol Plant. 2013; 148: 133-145.

30. Wani SH, Kumar V, Shriram V, Sah SK. Phytohormones and their metabolic engineering for abiotic stress tolerance in crop plants. Crop J. 2016; 4:162-176.

31. Zwack PJ, Rashotte AM. Interactions between cytokinin signaling and abiotic stress responses. J Exp Bot. 2015; 66: 4863-4871.

32. Sudesh KY. Cold stress tolerance mechanisms in plants. A review. Agronomy for Sustainable Development Agron. Sustain. 2010; 515-527

33. Foolad MR, and Lin G Y. Relationship between cold tolerance during seed germination and vegetative growth in tomato: germplasm evaluation. J Amer Soc Hort Sci. 2000; 125: 679-83.

34. Charles WB, Harris RE. Tomato fruit-set at high and low temperatures. Can J Plant Sci. 1972; 52: 497.

35. Chinnusamy $\mathrm{V}$, Zhu J. and Zhu J-K. Cold stress regulation of gene expression in plants. TREND in Plant Science. 2007; 12

36. Thomashow MF. Role of Cold-Responsive Genes in Plant Freezing Tolerance. Plant Physiol. 1998; 118: 1-7.

37. Lynch DV. Chilling injury in plants: the relevance of membrane lipids, in: Katterman F. (Ed.), Environmental Injury to Plants, Academic Press, New York, 1990; 17-34.I

38. Hopkins WG. The physiology of plants under stress, in: Introduction to Plant Physiology, $2^{\text {nd }}$ ed., Wiley, New York. 1999; 451-475.

39. Steponkus PL, Uemura M, Webb MS. A contrast of the cryostability of the plasma membrane of winter rye and spring oat-two species that widely differ in their freezing tolerance and plasma membrane lipid composition, in: Steponkus P.L. (Ed.), Advances in Low-Temperature Biology, Press, London. 1993; 2: 211-312.

40. Uemura M, Steponkus P.L. Effect of cold acclimation on membrane lipid composition and freeze induced membrane destabilization, in: Plant Cold Hardiness, Molecular Biology, Biochemistry and 
Physiology, Plenum New York. 1997; 171-79.

41. Welti R, Li W., Li M., Sang Y., Biesiada H., Zhou H.E., Rajashekar C.B., Williams T.D., Wang $X$. Profiling membrane lipids in plant stress responses. Role of phospholipase $\mathrm{Da}$ in freezing induced lipid changes in Arabidopsis, J. Biol. Chem. 2002; 277: 31994 - 32002.

42. Shinozaki K, Yamaguchi-Shinozaki K. Molecular responses to dehydration and low temperature: differences and cross-talk between two stress signaling pathways, Curr. Opin. Plant Biol. 2000; $3: 217$.

43. Hansen J, Türk R, Vogg G, Heim R, Beck E. Conifer carbohydrate physiology: Updating classical views, in: Rennenberg H., Eschrich W., Ziegler H. (Eds.), Trees - Contributions to Modern Tree Physiology, Leiden: Backhuys Publisher. 1997; 97-108.

44. Frankow-Lindberg BE. Adaptation to winter stress in nine white clover populations: changes in non-structural carbohydrates during exposure to simulated winter conditions and 'spring' regrowth potential, Ann. Bot. 2001; 88: 745-751.

45. Baek KH, Skinner DZ. Alteration of antioxidant enzyme gene expression during cold acclimation of near-isogenic wheat lines, Plant Sci. 2003; 165:1221-1227

46. Hannah MA, Wiese D, Freund S, Fiehn O, Heyer AG, Hincha DK. Natural genetic variation of freezing tolerance in Arabidopsis, Plant Physiol. 2006; 142: 98-112.

47. Anchordoguy TJ, Alan SR, Carpenter JF, Crowe JH. Modes of interaction of cryoprotectants with membrane phospholipids during freezing. Cryobiology. 1987; 24: 324-331.

48. Epand RM, Shai Y, Segrest JP, Anantharamalah GM. Mechanisms for the modulation of membrane bilayer properties by amphipathic helical peptides. Biopolymers. 1995; 37:319-338.

49. Aroca R, Irigoyen JJ, Sanchezdiaz M. Drought enhances maize chilling tolerance. II. Photosynthetic traits and protective mechanisms against oxidative stress. Physiol. Plant. 2003; 117: 540- 549.

50. Livingston DP, Henson CA. Apoplastic sugars, fructans, fructan exohydrolase, and invertase in winter oat: responses to second-phase cold hardening. Plant Physio. 1998; 116: 403-408.

51. Aghdam MS, Asghari MR, Moradbeygi H, Mohammadkhani N, Mohayeji M and Rezapour-Fard J. Effect of postharvest salicylic acid treatment on reducing chilling injury in tomato fruit. Rom Biotechnol Lett. 2012; 17: 7466-73.

52. Javaheri M, Mashayekhi K, Dedham A and Zaker-Tavallaee F. Effects of salicylic acid on yield and quality characters of tomato fruit (Lycopersicon esculentum Mill.). Intl J Agric Crop Sci. 2012; 4: 1184-87.

53. Zarghami M, Shoor M, Ganjali A, Moshtaghi N and Tehranifar A. Effect of salicylic acid on morphological and ornamental characteristics of Petunia hybrida at drought stress. Ind J Fund Appl Life Sci 2014; 4: 523-32.

54. Shakirova FM, Sakhabutdinova AR, Bezrukova MV, Fatkhutdinova RA and Fatkhutdinova DR. Changes in the hormonal status of wheat seedlings induced by salicylic acid and salinity. Plant Sci. 2003; 164: 317.

55. Chandra A, Anand A and Dubey A. Effect of salicylic acid on morphological and biochemical attributes in cowpea. J Environ Biol. 2007; 28:193-96.

56. Miura K, Ohta M. SIZ1 a small ubiquitin-related modifier ligase, controls cold signaling through regulation of salicylic acid accumulation. J Plant Physiol. 2010; 167:555-560.

57. Finkelstein RR, Gampala SSL, Rock CD. Abscisic acid signaling in seeds and seedlings. Plant Cell Online. 2002; 14:S15-S45.

58. Yogendra K, Meena and Nirmaljit K. Salicylic Acid Enhanced Low Temperature Stress Tolerance in Vegetables: A Review. Chem Sci Rev Lett. 2017; 6: 2428-2435

59. Dalal M, Tayal D, Chinnusamy V, Bansal KC. Abiotic stress and ABAinducible Group 4 LEA from Brassica napus plays a key role in salt and drought tolerance. J Biotechnol. 2009. 139:137-145.

60. Leung J, Giraudat J. Abscisic acid signal transduction. Annu Rev Plant Physiol Plant Mol Biol. 1998; 49:199-222.

61. Nayyar H, Bains, TS and Kumar S. Chilling stressed chick- pea seedlings: effect of cold acclimation, calcium and abscisic acid on cryoprotective solutes and oxidative damage. Environ. Exp.Bot. 2005; 54: 275-285

62. Janowiak F, Luck E, and Dorffling K. Chilling tolerance of maize Seedlings in the field during cold periods in spring is related toc hilling-Induced increase in abscisic acid level. J. Agron. Crop Sci. 2003; 189: 156-161

63. Sayyari M, Babalar M, Kalantari S, Martínez-Romero D, Guillén F, Serrano M, Valero D. Vapour treatments with methyl salicylate or methyl jasmonate alleviated chilling injury and enhanced antioxidant potential during postharvest storage of pomegranates. Food Chem. 2011; 124: 964-970.

64. Zhao ML, Wang JN, Shan W, Fan JG, Kuang JF, Wu KQ, Li XP, Chen WX, He FY, Chen JY. 2013. Induction of jasmonate signalling regulators MaMYC2s and their physical interactions with MaICE1 in methyl jasmonate-induced chilling tolerance in banana fruit. Plant Cell Environ. 2013; 36:30-51

65. Hu Y, Jiang L, Wang F, Yu D. Jasmonate regulates the inducer of CBF expression-c repeat binding factor/DRE binding factor1 cascade and freezing tolerance in Arabidopsis. Plant Cell. 2013;25:2907-2924

66. Kolaksazov M, Laporte F, Ananieva K, Dobrev P, Herzog M, Ananiev ED. Effect of chilling and freezing stresses on jasmonate content in Arabis alpina. Bulgarian J Agri Sci. 2013; 19:15-17

67. Achard P, Gong F, Cheminant S, Alioua M, Hedden P, Genschik P. The cold-inducible CBF1 factor-dependent signaling pathway modulates the accumulation of the growth-repressing DELLA proteins via its effect on gibberellin metabolism. Plant Cell. 2008; 20:2117-2129.

68. Claeys H, De Bodt S, Inzé D. Gibberellins and DELLAs: central nodes in growth regulatory networks. Trends Plant Sci. 2014; 19:231-239.

69. Hu X, Xin L, Sun L, Fu Z. Toxic effects of chlorpyrifos on cucumber and brassinosteroid-mediated responses under the conditions of chilling temperature and low light. Asian Journal of Ecotoxicology. 2013; 8: 513-520.

70. Aghdam MS, Asghari M, Farmani B, Mohayeji M, Moradbeygi H. Impact of postharvest brassinosteroids treatment on PAL activity in tomato fruit in response to chilling stress. Sci Hortic (Amsterdam) 2012; 144: 116-120.

71. Wang Q, Ding T, Gao L, Pang J, Yang N. Effect of brassinolide on chilling injury of green bell pepper in storage. Sci Hortic (Amsterdam). 2013; 144: 195-200

72. Kamuro Y, Takatsuto S. Practical applications of brassinosteroids in agricultural fields. In: Sakurai A, Yokota T, Clouse SD (eds). Brassinosteroids-Steroidal Plant Hormones. Springer-Verlag. 1999: 223-241

73. Wu XX, Ding HD, Chen JL, Zhu ZW, Zha DS. Exogenous spray application of 24-epibrassinolide induced changes in photosynthesis and antioxidant defences against chilling stress in eggplant (Solanum melongena L.) seedlings. J Hortic Sci Biotechnol. 2015; 90: 217-225.

74. Parmar, Nehanjali, Kunwar Harendra Singh, Deepika Sharma, Lal Singh, Pankaj Kumar, J. Nanjundan, Yasin JK, Devendra Kumar C, Ajay Kumar T. Genetic engineering strategies for biotic and abiotic stress tolerance and quality enhancement in horticultural crops: a comprehensive review. 3 Biotech, 2017; 7: 239.

75. Zhu T, and Provart NJ. Transcriptional responses to low temperature and their regulation in Arabidopsis. Canadian Journal of Botany-Revue Canadienne de Botanique. 2003; 81, 1168-1174

76. Lee B-H, Henderson DA, and Zhu J-K. The Arabidopsis coldresponsive transcriptome and its regulation by ICE1. Plant Cell. 2005; 17: 3155-3175

77. Fan W, Zhang M, Zhang H, Zhang P. Improved tolerance to various abiotic stresses in transgenic sweet potato (/pomoea batatas) expressing spinach betaine aldehyde dehydrogenase. PLoS One. 2012; $7:$ e37344.

78. Altieri MA, Nicholls $\mathrm{Cl}$, Henao A, Lana MA. Agroecology and the design of climate change-resilient farming systems. Agronomy for Sustainable Development. 2015; 35: 869-890.

79. Pereira JS, Chaves MM. Plant responses to drought under climate change in Mediterranean-type ecosystems. In: Global change and Mediterranean-type ecosystems. 2007; 140 -160. 